Tatjana Peković, dipl. inž.

\section{PRIHOD KAO OPŠTIJI KRITERIJUM OPTIMIZACIJE U ODNOSU NA RASPOLOZ̆IVOST I TROŠKOVE ZAMENA PRI ODREDIVANJU OPTIMALNOG PERIODA PREVENTIVNE ZAMENE}

UDC: $62-7.001: 519.86$

Rezime:

U ovom radu dat je postupak za određivanje optimalnog perioda preventivne zamene elementa sa rastucim tokom otkaza kada je kriterijum optimizacije prihod po jedinici vremena. Pokazano je da su prihod po jedinici vremena $i$ njegova komplementarna veličina zbir gubitka zbog zastoja sistema $i$ troškova zamena, opštiji kriterijumi optimizacije od minimalnih troškova zamena $i$ maksimalne raspoloživosti $i$ da predstavljaju samo posebne slučajeve oba komplementarna kriterijuma. Predloženo je da se ovo svojstvo primeni i na tehničke sisteme kod kojih nije definisan prihod po jedinici vremena rada, uvodenjem koeficijenta značaja ispravnosti rada (raspoloživosti) u odnosu na troškove zamena, kao kompromisnog kriterijuma. Izvedeni su izrazi za ekvivalentne parametre pouzdanosti elemenata sa rastućim tokom otkaza, cime je omogućena analiza pouzdanosti $i$ raspoloživosti tehničkih sistema koji sadrže takve elemente u uslovima uspostavljenog procesa njihove preventivne zamene. Urađen je program za računar čijim korišćenjem su, za date ulazne podatke, dobijene brojčane vrednosti svih parametara za sva tri kriterijuma optimizacije.

Ključne reči: inženjerstvo održavanja, optimalni period preventivne zamene, troškovi zamena, raspoloživost.

\title{
INCOME AS A WORE GENERAL OPTIMIZATION CRITERION AS REGARDS AVAILABILITY AND REPLACEMENT COSTS IN DETERMINING THE OPTIMAL PERIOD OF PREVENTIVE REPLACEMENT
}

\section{Summary:}

This paper descubes a procedure for determining the optimal period of pre ventive replacement of elements with increasing failure rate when the criterion is income per operating time unit. It is shown that income per operating time unit and its complementary value of the sum of losses due to system dwell and re. placement costs represent more general optimization criteria than minimal replacement costs and maximal availability; they also represent only separated cases of both complementary criteria. This property is suggested to be applied in technical systems without a dehued income per operating time unit by introducting the coefficient of correct operation importance (availability) in relation to replacement costs as a compromising criterion The expressions for equivalent parameters of reliability of elements with increasing failure rate are derived which enables the analysis of reliability and availability of technical systems with these elements in the conditions of the re-established process of their preventive replacement. The realized software program gives numerical values
of all parameters for all optimization criteria.

Key words: maintenance engineering, optimal period for preventive replacement, replacement costs, availability. 


\section{Uvod}

Realnost da se i u savremenim tehničkim sistemima ne može izbeći $u$ gradnja elemenata sa rastućim tokom otkaza čije je srednje vreme do otkaza znatno kraće od srednjeg vremena do otkaza ostalih elemenata zahteva da se, $u$ okviru aktivnosti celokupnog tehničkog održavanja, planiraju i aktivnosti preventivnih zamena tih elemenata. Zamenom elemenata sa rastućim tokom otkaza postiže se obnavljanje sistema i sprečavanje njihovih čestih zastoja.

Posle kog vremena je najpogodnije izvršiti zamenu elemenata sa rastućim tokom otkaza zavisi od karakteristika pouzdanosti elemenata (gustina raspodele verovatnoće vremena do otkaza, trenutna vrednost toka otkaza, srednje vreme do pojave otkaza), trošenja resursa pri vršenju zamena (vremena potrebna za obavljanje zamena, materijalni i finansijski troškovi) i veličine koja se želi optimizirati (kriterijum optimizacije).

U stranoj i domaćoj naučnoj literaturi $u$ oblasti inženjerstva održavanja, definisan je $i$ ispitan veliki broj matematičkih modela i postupaka za dobijanje najpovoljnijeg (optimalnog) perioda preventivne zamene za različite strategije obavljanja preventivnih zamena. Kao kriterijum optimizacije najčešce su uzimani troškovi zame po jedinici vremena rada, tako da su preventivne zamene obavljane po isteku tako dobijenog perioda zamene, obezbeđivale postizanje minimalnih troškova zamena. U znatno manjem broju radova kao kriterijum optimizacije uzimana je raspoloživost, kako bi se preventivnim zamenama postiglo da $\mathrm{u}$ toku eksploatacije raspoloživost ima maksimalnu moguću vrednost.

U ovom radu je, za slučaj kombinovane preventivne zamene (Age replacement), kao kriterijum optimizacije uzet prihod po jedinici vremena, kao razlika nadoknade koja se dobija za svaki čas rada sistema i troškova zamena po času rada. Kao kriterijum optimizacije može se uzeti i komplementarna veličina, koja predstavlja zbir troškova zamena i izgubljene dobiti zbog zastoja u radu sistema. Međutim, $i$ ako se radi o dve različite veličine, one kao kriterijum optimizacije daju isti rezultat, pošto im je zbir jednak konstanti i kada prva veličina ima maksimum, druga ima minimum i obrnuto. Matematički modeli koji daju vezu između karakteristika pouzdanosti elemenata sa rastućom vrednošću toka otkaza, potrebnog vremena za vršenje zamena i troškova koji se pri tome čine, dati su u zavisnosti od perioda preventivne zamene, tako da se ponašanje veličina koje su od interesa može analizirati u celom opsegu promena perioda preventivne zamene, a ne samo u tačkama optimuma za pojedine kriterijume optimizacije. Definisan je veći broj pokazatelja preko kojih se može ustanoviti kakvi se rezultati postižu vršenjem preventivnih zamena.

$\mathrm{Na}$ brojčanom primeru elemenata sa rastućim tokom otkaza, čija raspodela verovatnoće vremena do otkaza podleže Vejbulovoj raspodeli, dat je postupak korišćenja izvedenih izraza, izvršena je analiza dobijenih rezultata i ustanovljene su veze $i$ zavisnosti između pojedinih veličina kojih nema $u$ dostupnoj naučno-stručnoj literaturi, a značajne su za rešavanje problema koji se javljaju u praksi inženjerstva održavanja.

Korišćene oznake:

$\mathrm{f}(\mathrm{t})$ - gustina verovatnoće vremena do pojave otkaza,

$\mathrm{F}(\mathrm{t})$ - raspodela verovatnoće vremena do pojave otkaza,

$\mathrm{R}(\mathrm{t})$ - pouzdanost elementa (verovatnoća da će raditi bez otkaza do trenutka t),

$\beta, \eta \quad$ - parametri (oblika i razmere) Vejbulove raspodele,

$\mathrm{K}_{\beta} \quad$ - vrednost $\Gamma$ funkcije $\Gamma(1+1 / \beta)$, 
$\lambda(\mathrm{t}) \quad$ - trenutni tok otkaza,

$\mathrm{m}_{\mathrm{k}} \quad$ - srednje vreme do otkaza kada se ne vrše preventivne zamene,

$\mathrm{m}(\mathrm{t})$ - srednje vreme do zamene, bilo korektivne bilo preventivne,

$\mathrm{T}_{\mathrm{k}} \quad$-- srednje vreme trajanja korektivne zamene elementa sa rastućim tokom otkaza,

$\mathrm{T}_{\mathrm{p}} \quad$ - srednje vreme trajanja preventivne zamene elementa sa rastućim tokom otkaza,

$\mathrm{T}_{\mathrm{os}}^{-} \quad$ - srednje vreme trajanja popravke elementa sa rastućim tokom otkaza,

$M_{k} \quad$ - srednje vreme između zamena kada se ne vrše preventivne zamene,

$\mathrm{M}(\mathrm{t})$ - srednje vreme između zamena kada se vrše i preventivne zamene,

$\mathrm{T}_{\mathrm{i}} \quad$ - optimalna vrednost perioda preventivne zamene $\quad(i=$ $=\mathrm{c}, \mathrm{a}, \mathrm{d}$ ),

$\mathrm{C}_{\mathrm{k}} \quad$ - troškovi korektivne zamene elementa sa rastućim tokom otkaza,

$\mathrm{C}_{\mathrm{p}}$ - troškovi preventivne zamene elementa sa rastućim tokom otkaza,

$\mathrm{C}_{\mathrm{os}} \quad$ - troškovi popravke elementa sa konstantnim tokom otkaza,

$\mathrm{D}_{\mathrm{o}}$ - prihod po jedinici vremena rada,

$\mathrm{C}(\mathrm{T})$ - troškovi po jedinici vremena rada,

$\mathrm{A}(\mathrm{T})$ - raspoloživost,

$\dot{\mathrm{D}}(\mathrm{T})$ - prihod po jedinici vremena,

$\overline{\mathrm{D}}(\mathrm{T})$ - gubici zbog zastoja i troškova zamene,

$\mathrm{L}_{\mathrm{i}}(\mathrm{T})$ - funkcije koje sadrže optimalna rešenja $T_{i}(i=c, a, d)$,

$\mathrm{C}_{\mathrm{r}}(\mathrm{T})$ - relativna vrednost troškova $\mathrm{u}$ odnosu na troškove kada se preventivne zamene ne vrše,
$A_{r}(T)$ - relativna raspoloživost $u$ odnosu na raspoloživost kada se preventivne zamene vrše,

$\mathrm{D}_{\mathrm{r}}(\mathrm{T})$ - relativni prihod $\mathrm{u}$ odnosu na prihod kada se prev. zamene ne vrše,

$\mathrm{G}_{\mathrm{i}}(\mathrm{T})$ - dobit izražena u procentima koja se dobija prev. zamenama $(i=c, a, d)$,

$\mathrm{g}(\mathrm{T})$ - dobit izražena $\mathrm{u}$ procentima u odnosu na dobit pri optimalnim preventivnim zamenama,

$\mathrm{z}(\mathrm{T})$ - intenzitet korektivnih zamena,

$\mathrm{u}(\mathrm{T})$ - intenzitet preventivnih zamena,

$\mathrm{v}(\mathrm{T})$ - srednje vreme do korektivne zamene,

$\mathrm{w}(\mathrm{T})$ - srednje vreme do preventivne zamene,

$\mathrm{T}_{\mathrm{e}} \quad$ - period eksploatacije,

$\mathrm{T}_{\mathrm{ks}} \quad$ - srednje vreme zamene elemenata sistema kada se ne vrše preventivne zamene,

$\mathrm{T}_{\mathrm{s}} \quad-$ srednje vreme zamene elemenata sistema kada se vrše preventivne zamene,

$R_{k s}(T)$ - pouzdanost sistema kada se ne vrše preventivne zamene,

$\mathrm{R}_{\mathrm{s}}(\mathrm{T})$ - pouzdanost sistema kada se vrše preventivne zamene,

$A_{k s}(T)$ - raspoloživost sistema kada se ne vrše preventivne zamene,

$\mathrm{A}_{\mathrm{s}}(\mathrm{T})$ - raspoloživost sistema kada . se vrše preventivne zamene,

$\mathrm{C}_{\mathrm{ks}}(\mathrm{T})$ - troškovi zamena elemenata sistema po jedinici vremena rada kada se preventivne zamene ne vrše,

$\mathrm{C}_{s}(\mathrm{~T})$ - troškovi zamena elemenata sistema po jedinici vremena rada kada se vrše preventivne zamene,

$\mathrm{N}_{\mathrm{k}}$ - srednji broj zamena elemenata sa rastućim tokom otkaza kada se preventivne zamene ne vrše, 
$\mathrm{N}_{\mathrm{ek}}$ - srednji broj korektivnih zamena elemenata sa rastućim tokom otkaza,

$\mathrm{N}_{\text {ep }} \quad$ - srednji broj preventivnih zamena elemenata sa rastućim tokom otkaza,

$\mathrm{N}_{\mathrm{e}} \quad$ - srednji broj zamena elemenata sa rastućim tokom otkaza,

$\mathrm{n}_{\mathrm{e}}$

- odnos broja korektivnih zamena elemenata sa rastućim tokom otkaza kada se preventivne zamene vrše i kada se ne vrše,

$\mathrm{N}_{\mathrm{oo}}$ - srednji broj zamena elemenata sa konstantnim tokom otkaza kada se ne vrše preventivne zamene,

$\mathrm{N}_{\mathrm{oe}} \quad$ - srednji broj zamena elemenata sa rastućim tokom otkaza $u$ sistemu kada se ne vrše preventivne zamene,

$\mathrm{N}_{\mathrm{ok}} \quad$ - srednji broj zamena elemenata sistema kada se ne vrše preventivne zamene,

$\mathrm{N}_{\text {os }}$ - srednji broj zamena elemenata sa konstantnim tokom otkaza kada se vrše preventivne zamene,

$\mathrm{N}_{\mathrm{sk}} \quad$ - srednji broj korektivnih zamena elementa sa rastućim tokom otkaza $u$ sistemu kada se vrše preventivne zamene,

$\mathrm{N}_{\mathrm{sp}} \quad$ - srednji broj preventivnih zamena elemenata sa rastućim tokom otkaza u sistemu kada se vrše preventivne zamene,

$\mathrm{N}_{\mathrm{s}} \quad$ - srednji broj zamena elemenata sistema,

$\mathrm{n}_{\mathrm{s}} \quad$ - odnos broja korektivnih zamena elemenata sistema kada se preventivne zamene ne vrše i kada se vrše.

\section{Odreåivanje optimalnog perioda preventivne zamene tako da prihod ima maksimalnu vrednost}

Prilikom definisanja aktivnosti održavanja tehničkog sistema koji čine npr. jedna komponenta sa rastućom vrednošću toka otkaza $\lambda(t)$ i ostatak sistema koji se sastoji od komponenata sa konstantnim tokom otkaza, ukupne vrednosti $\lambda_{\text {os }}$ unapred se može reći da za komponente ostatka sistema treba obezbediti samo zamene u slučaju da otkažu (korektivne zamene), dok za komponentu sa rastućim tokom otkaza, pored korektivnih, treba predvideti i preventivne zamene.

Kombinovana preventivna zamena (Age Replacement) elemenata sa rastućom vrednošću toka otkaza vrši se posle planiranog vremena $T$. Ukoliko se dogodi da element otkaže pre isteka vremena $T$ (pretpostavlja se da je indikacija otkaza trenutna) zamenjuje se (korektivno), a trenutak u kome će biti izvršena preventivna zamena odlaže se, tako da ona bude posle isteka vremena $T$ računato od poslednje zamene. Na taj način proces se nastavlja dalje. To znači da se preventivna zamena vrši kada element dostigne određenu "starost « u radu, računato od poslednje zamene, bilo da je ona bila preventivna ili korektivna.

Kada se komponenta sa rastućom trenutnom vrednošću toka otkaza, po isteku planiranog vremena $T$ preventivno zameni utroši se neko vreme $T_{p}$ i načine troškovi $C_{p}$. U slučaju da komponenta otkaže pre isteka vremena $\mathrm{T}$ vrši se njena korektivna zamena, pri čemu se utroši vreme $T_{k}$ i načine troškovi $C_{k}$. $U$ praksi je $T_{p}<T_{k}$ i $C_{p}<C_{k}$, jer se preventivna zamena vrši $u$ planiranim uslovima i u planiranom trenutku, dok se vreme i uslovi korektivne zamene ne mogu predvideti i birati tako da dolazi do dodatnih gubitaka vremena i troškova. Kada se dogodi otkaz mobilnog sredstva na terenu, na primer, mora se obaviti transport opreme i ekipe za održavanje na mesto na kojem se javio otkaz, a sa- 
ma zamena se obavlja $u$ otežanim uslovima ili se mora angažovati drugo vozilo koje ce transportovati ono koje je otkazalo u radionicu.

Za otklanjanje otkaza neke od komponenata sa konstantnom vrednošću toka otkaza potrebno je vreme $T_{\text {os }} \mathrm{i}$ čine se troškovi $\mathrm{C}_{\text {os. }}$.

Treba odrediti period preventivne zamene komponente sa rastućom vrednošću toka otkaza $\lambda(\mathrm{t})$ tako da $\mathrm{u}$ kupni prihod po jedinici vremena bude maksimalan, ako je $D_{0}$ suma koja se dobija po jedinici vremena ispravnog rada tehničkog sistema.

To je opštiji pristup od slučaja kada se uzima [9] da je $C_{k}=c_{k} T_{k}$ i $C_{p}=$ $=c_{p} T_{p}$, jer troškovi zamena $u$ opštem slučaju nisu srazmerni vremenima potrebnim za obavljanje tih zamena (jedan od razloga je upravo cena rezervnog dela). U praksi se može ići preko srednjih vrednosti koje te veličine imaju u realnim procesima održavanja:

$$
X=\frac{\sum_{i=1}^{n} x_{i}}{n}
$$

gde $\mathrm{X}$ može biti $\mathrm{T}_{\mathrm{p}}, \mathrm{T}_{\mathrm{k}}, \mathrm{T}_{\mathrm{os}}, \mathrm{C}_{\mathrm{p}}, \mathrm{C}_{\mathrm{k}} \mathbf{i}$ $\mathrm{C}_{\text {os. }}$ Prilikom prvih proračuna procenjuje se na osnovu prethodnih podataka $i$ iskustva, a zatim se dobijeni rezultati koriguju prema vrednostima koje realno imaju. Pored toga, izrazi koji će biti izvedeni omogućavaju da se prilikom postavljanja procesa održavanja datog tehničkog sistema izvrši analiza osetljivosti dobijenih rezultata, $\mathrm{tj}$. koliko se oni menjaju $\mathrm{u}$ zavisnosti od promene (pogrešne procene) ulaznih veličina.

Optimalni period preventivne zamene komponente sa rastućom vrednošću toka otkaza

Na osnovu datog opisa procesa preventivne zamene može se zaključiti da verovatnoća da će se po isteku vremena $\mathrm{T}$ obaviti preventivna zamena elementa sa rastućim tokom otkaza iznosi $R(T)$, a verovatnoća da će ranije doći do otkaza i da će se izvršiti korektivna zamena je $F(T)$. Srednje vreme između zamena $M$ je:

$M(T)=m(T)+F(T) T_{k}+R(T) T_{p}$

gde je:

$$
m(t)=\int_{0}^{T} R(t) d t
$$

Raspoloživost je data izrazom:

$$
\begin{aligned}
& A(T)=\frac{m(T)}{m(T)+F(T) T_{k}+R(T) T_{p}}= \\
& =\frac{1}{1+\frac{F(T)}{m(T)} T_{k}+\frac{R(T)}{m(T)} T_{p}}
\end{aligned}
$$

Ukupni troškovi zamena (preventivnih i korektivnih) po jedinici vremena rada su:

$$
C(T)=\frac{F(T) C_{k}+R(T) C_{p}}{m(T)}
$$

Prihod od rada sistema, izražen po jedinici vremena, srazmeran je raspoloživosti, pri čemu je koeficijent srazmernosti razlika veličina prihoda i troškova koja je data po jedinici vremena rada, tako da se može napisati:

$$
\begin{aligned}
& D(T)=A(T)\left[D_{0}-C(T)\right]= \\
& =\frac{D_{0}-\frac{F(T) C_{k}+R(T) C_{p}}{m(T)}}{1+\frac{F(T)}{m(T)} T_{k}+\frac{R(T)}{m(T)} T_{p}}
\end{aligned}
$$

ili u obliku:

$$
D(T)=\frac{m(T) D_{0}-F(T) C_{k}-R(T) C_{p}}{m(T)+F(T) T_{k}+R(T) T_{p}}
$$


Na sličan način može se definisati i veličina komplementarna prihodu kao zbir gubitaka zbog neraspoloživo-

$$
\begin{aligned}
& \bar{D}(T)=\frac{F(T) C_{k}+R(T) C_{p}+D_{0} F(T) T_{k}+D_{0} R(T) T_{p}}{m(T)+F(T) T_{k}+R(T) T_{p}}= \\
& =\frac{D_{0} T_{k}+C_{k}-R(T)\left[D_{0}\left(T_{k}-T_{p}\right)+C_{k}-C_{p}\right]}{m(T)+F(T) T_{k}+R(T) T_{p}}
\end{aligned}
$$

Maksimalna vrednost prihoda dobija se kada je ispunjen uslov:

$$
\frac{\mathrm{dD}(\mathrm{T})}{\mathrm{dT}}=0
$$

koji se posle diferenciranja izraza (7) i svih svođenja može napisati u obli$\mathrm{ku}$ :

$$
\begin{aligned}
& \lambda(T) m(T)+\lambda(T) \frac{C_{k} T_{p}-C_{p} T_{p}}{D_{0}\left(T_{k}-T_{p}\right)+C_{k}-C_{p}}+ \\
& +R(T)=\frac{D_{0} T_{k}+C_{k}}{D_{0}\left(T_{k}-T_{p}\right)+C_{k}-C_{p}}
\end{aligned}
$$

Minimum gubitaka (zbir troškova i izgubljene dobiti zbog zastoja) dobija se iz uslova:

$$
\frac{\mathrm{d} \overline{\mathrm{D}}(\mathrm{T})}{\mathrm{dT}}=0
$$

i posle diferenciranja izraza (8) i svih sređivanja dobija se izraz (9) kao i za maksimalni prihod, što se moglo i očekivati.

Vrednost $\mathrm{T}=\mathrm{T}_{\mathrm{d}}$, koja zadovoljava uslov (9), predstavlja optimalni period preventivne zamene pri kome ukupni prihod ima maksimalnu, a gubici minimalnu vrednost.

Srednje vreme do zamene : $u$ tom slučaju, bilo korektivne bilo preventivne, iznosi:

$$
\mathrm{m}_{\mathrm{d}}=\int_{0}^{\mathrm{T}_{\mathrm{d}}} \mathrm{R}(\mathrm{t}) \mathrm{dt}
$$

Ako se vrednost za $\mathrm{m}_{\mathrm{d}}$ iz uslova (9) zameni u (7) dobija se:

$$
D_{d}=\frac{D_{0}-\left(C_{k}-C_{p}\right) \lambda\left(T_{d}\right)}{1+\left(T_{k}-T_{p}\right) \lambda\left(T_{d}\right)}
$$

sti (izgubljena dobit) i troškova zamena: što znači da se optimalna vrednost perioda preventivne zamene može naći kao presek krive (7) i krive:

$$
\mathrm{L}_{\mathrm{d}}(\mathrm{T})=\frac{\mathrm{D}_{0}-\left(\mathrm{C}_{\mathrm{k}}-\mathrm{C}_{\mathrm{p}}\right) \lambda(\mathrm{T})}{1+\left(\mathrm{T}_{\mathrm{k}}-\mathrm{T}_{\mathrm{p}}\right) \lambda(\mathrm{T})}
$$

Minimalni troškovi zamena po jedinici vremena rada dobijaju se, kao što je izvedeno u [5] iz uslova:

$$
\mathrm{m}(\mathrm{T}) \lambda(\mathrm{T})+\mathrm{R}(\mathrm{T})=\frac{\mathrm{C}_{\mathrm{k}}}{\mathrm{C}_{\mathrm{k}}-\mathrm{C}_{\mathrm{p}}}
$$

Kada se vrednost za $\mathrm{m}(\mathrm{T})$ iz (13) zameni u (5) dobija se:

$$
\mathrm{C}_{\mathrm{c}}=\lambda\left(\mathrm{T}_{\mathrm{c}}\right)\left(\mathrm{C}_{\mathrm{k}}-\mathrm{C}_{\mathrm{p}}\right)
$$

što znači da se vrednost perioda preventivne zamene $T=T_{c}$, pri čemu troškovi preventivnih zamena imaju minimalnu vrednost, mogu naći kao presek krive (5) i krive:

$$
\mathrm{L}_{\mathrm{c}}(\mathrm{T})=\lambda(\mathrm{T})\left(\mathrm{C}_{\mathrm{k}}-\mathrm{C}_{\mathrm{p}}\right)
$$

$\mathrm{Na}$ isti način maksimalna raspoloživost se dobija iz uslova $\frac{\mathrm{dA}(\mathrm{T})}{\mathrm{dT}}=0$, koji se posle diferenciranja izraza (4) i sređivanja može napisati u obliku:

$$
m(T) \lambda(T)+R(T)=\frac{T_{k}}{T_{k}-T_{p}}
$$

a optimalna vrednost perioda preventivne zamene $T=T_{a}$ pri kojoj raspoloživost ima maksimalnu vrednost može se dobiti kao presek krive (4) i krive date izrazom:

$$
\mathrm{L}_{\mathrm{a}}(\mathrm{T})=\frac{1}{1+\lambda(\mathrm{T})\left(\mathrm{T}_{\mathrm{k}}-\mathrm{T}_{\mathrm{p}}\right)}
$$


U slučajevima kada je $D_{0}$ veliko $\mathrm{u}$ odnosu na $\mathrm{C}_{\mathrm{k}} / \mathrm{m}(\mathrm{T})$ i $\mathrm{C}_{\mathrm{p}} / \mathrm{m}(\mathrm{T}) \quad(\mathrm{t} \mathrm{j}$. $D_{o} \rightarrow \infty$ ), uslov (9) postaje (16), što znači da je uslov za optimalnu raspoloživost poseban slučaj uslova za optimalnu vrednost prihoda, kada je značaj raspoloživosti znatno veći od značaja koji imaju troškovi zamena.

U slučaju da je prihod po jedinici vremena rada veoma mali, tj. $D_{o} \rightarrow 0$, iz (9) se dobija:

$$
\begin{aligned}
& \lambda(T) m(T)+\lambda(T) \frac{C_{k} T_{p}-C_{p} T_{k}}{C_{k}-C_{p}}+R(T)= \\
& =\frac{C_{k}}{C_{k}-C_{p}}
\end{aligned}
$$

Izraz (18) nije isti kao izraz (13). $\mathrm{Da}$ bi se to postiglo potrebno je da bude ispunjen dodatni uslov:

$$
\begin{aligned}
& \frac{\mathrm{D}_{0} \mathrm{~T}_{k}+\mathrm{C}_{k}}{\mathrm{D}_{0}\left(\mathrm{~T}_{k}-\mathrm{T}_{\mathrm{p}}\right)+\mathrm{C}_{\mathrm{k}}-\mathrm{C}_{\mathrm{p}}}-\lambda(\mathrm{T}) . \\
& \cdot \frac{\mathrm{C}_{k} \mathrm{~T}_{\mathrm{p}}-\mathrm{C}_{\mathrm{p}} \mathrm{T}_{\mathrm{k}}}{\mathrm{D}_{0}\left(\mathrm{~T}_{\mathrm{k}}-\mathrm{T}_{\mathrm{p}}\right)+\mathrm{C}_{\mathrm{k}}-\mathrm{C}_{\mathrm{p}}}=\frac{\mathrm{C}_{k}}{\mathrm{C}_{\mathrm{k}}-\mathrm{C}_{\mathrm{p}}}
\end{aligned}
$$

odakle se dobija da je potrebno da:

$$
D_{0}=\lambda(T)\left(C_{k}-C_{p}\right)=C_{c}
$$

To znači da je, u slučaju kada prihod po jedinici vremena rada ima istu vrednost kao troškovi zamena po jedinici vremena rada, period preventivne zamene pri kome prihod ima optimalnu (maksimalnu) vrednost isti kao period preventivne zamene pri kome troškovi po jedinici vremena rada imaju optimalnu (minimalnu) vrednost.

$\mathrm{Na}$ osnovu izvedenih izraza može se zaključiti da optimalna vrednost perioda preventivne zamene $T_{d}$ pri kojoj prihod po jedinici vremena ima maksimalnu vrednost, u opštem slučaju zavisi od $C_{p}, C_{k}, T_{p} i T_{k}$, ali da postoje vrednosti $D_{o}$ pri kojima ona ne zavisi od $C_{k}$ i $C_{p}$ (kada $D_{o}$ ima veliku vrednost $\mathrm{i}$ tada je period preventivne zamene $T_{a}$ ) i kada ne zavisi od
$T_{p}$ i $T_{k}\left(D_{o}=C_{c}\right.$ i tada je period preventivne zamene $\left.T_{c}\right)$. Ako je $T_{p} / T_{k}<C_{p} / C_{k}$ pri promeni $\mathrm{D}_{\mathrm{o}}$ od $\mathrm{C}_{\mathrm{c}}$ do $\infty$ optimalni period preventivne zamene menja se od $T_{a}$ do $T_{c}$, odnosno od $T_{c}$ do $T_{a}$ ako je $C_{p} / C_{k}<T_{p} / T_{k}$. Promena vrednosti prihoda po jedinici vremena rada od 0 do $C_{r}$ nije značajna za realne sisteme, jer u tom slučaju, kao što se iz (6) vidi, vrednost prihoda ima negativne vrednosti. U posebnom slučaju, kada je $T_{p} / T_{k}=C_{p} / C_{k}$, sve tri vrednosti optimalnog perioda preventivne zamene su međusobno jednake $\left(T_{a}=T_{d}=\right.$ $=T_{c}$ ) što se može zaključiti iz izraza (9), (13), (16) i (18) koji, u tom slučaju, izražavaju jedan isti uslov.

\section{Relativne vrednosti kriterijuma} optimizacije u odnosu na slučaj kada se preventivne zamene ne vrše

Da bi se ustanovilo šta se preventivnim zamenama elemenata sa rastućim tokom otkaza dobija, vrednosti kriterijuma optimizacije često se daju kao relativne vrednosti u odnosu na slučaj kada se preventivne zamene ne vrše $(T \rightarrow \infty)$. Tada se na osnovu (2), (3), (4), (5), (7) i (8) dobija:

$$
\begin{aligned}
& \mathrm{m}_{\mathrm{k}}=\int_{0}^{\infty} \mathrm{R}(\mathrm{t}) \mathrm{dt} \\
& \mathrm{M}_{\mathrm{k}}=\mathrm{m}_{\mathrm{k}}+\mathrm{T}_{\mathrm{k}} \\
& \mathrm{A}_{\mathrm{k}}=\frac{\mathrm{m}_{\mathrm{k}}}{\mathrm{M}_{\mathrm{k}}} \\
& \mathrm{C}_{\mathrm{ok}}=\frac{\mathrm{C}_{\mathrm{k}}}{\mathrm{m}_{\mathrm{k}}} \\
& \mathrm{D}_{\mathrm{k}}=\frac{\mathrm{m}_{\mathrm{k}} \mathrm{D}_{0}-\mathrm{C}_{\mathrm{k}}}{\mathrm{M}_{\mathrm{k}}} \\
& \mathrm{N}_{\mathrm{k}}=\frac{\mathrm{T}_{\mathrm{e}}}{\mathrm{M}_{\mathrm{k}}}
\end{aligned}
$$

Relativne vrednosti, kao i dobitak izražen u procentima za pojedine ve- 
ličine, u zavisnosti od perioda preventivne zamene dati su izrazima:

$$
\begin{aligned}
& A_{r}(T)=\frac{A(T)}{A_{k}} \\
& G_{a}(T)=\frac{A_{r}-A_{k}}{A_{k}} 100 \\
& g_{a}(T)=\frac{G_{a}(T)}{G_{a \max }} 100 \\
& C_{r}(T)=\frac{C(T)}{C_{o k}} \\
& G_{c}(T)=\frac{C_{o k}-C(T)}{C_{o k}} 100 \\
& g_{c}(T)=\frac{G_{c}(T)}{C_{c} \max } 100 \\
& D_{r}(T)=\frac{D(T)}{D_{k}} \\
& G_{d}(T)=\frac{D(T)-D_{k}}{D_{k}} 100 \\
& g_{d}(T)=\frac{G_{d}(T)}{G_{d} \max } 100
\end{aligned}
$$

Relativne vrednosti prihoda mogu biti date $i \mathrm{u}$ odnosu na vrednosti $\mathrm{D}_{0}$. Naime, sve tri veličine $D(T), \bar{D}(T)$ i $D_{0}$ izračunavaju se $u$ novčanim jedinicama po jedinici vremena rada i između njih postoji, kao što se može iz (7) i (8) vdeti, sledeća veza:

$$
\mathrm{D}(\mathrm{T})+\overline{\mathrm{D}}(\mathrm{T})=\mathrm{D}_{0}
$$

Sve mere koje se preduzimaju pri konstruisanju, proizvodnji i eksploataciji tehničkih sistema (od posebnog značaja su mere tehničkog održavanja uključujući i preventivne zamene) usmerene su na to da $D(T)$, bude što veće, a $\bar{D}(T)$ što manje. Zato odnos te dve veličine:

$$
d_{r}(T)=\frac{D(T)}{\bar{D}(T)}
$$

izražava, na neki način, rentabilnost tehničkog sistema i ona je utoliko veća ukoliko je taj odnos veći. Kako je odnos $d_{r}$ dat $u$ zavisnosti od dužine perioda preventivne zamene (36), treba istaći da, za date ulazne podatke, maksimalnu vrednost ima kada je ispunjen uslov (9), jer je ustanovljeno da tada $D(T)$ ima maksimalnu, a $D(T)$ minimalnu vrednost.

\section{Ekvivalentni parametri pouzdanosti elementa koji se preventivno zamenjuje}

Izrazi (4), (5) i (6) mogu se napisati u obliku:

$$
\begin{aligned}
& A(T)=\frac{1}{1+T_{k} z(T)+T_{p} u(T)} \\
& C(T)=C_{k} z(T)+C_{p} u(T) \\
& D(T)=\frac{D_{0}-C_{k} z(T)+C_{p} u(T)}{1+T_{k} z(T)+T_{p} u(T)} \\
& D(T)=\frac{\left(D_{0} T_{k}+C_{k}\right) z(T)+\left(D_{0} T_{p}+C_{p}\right) u(T)}{1+T_{k} z(T)+T_{p} u(T)}
\end{aligned}
$$

gde su $z(T)$ i $u(T)$ ekvivalentni intenziteti korektivnih i preventivnih zamena $u$ zavisnosti od perioda preventivne zamene:

$$
\begin{aligned}
& z(T)=\frac{F(T)}{m(T)} \\
& u(T)=\frac{R(T)}{m(T)}
\end{aligned}
$$

Ukupni intenzitet zamena (korektivnih i preventivnih) je:

$$
\mathrm{z}(\mathrm{T})+\mathrm{u}(\mathrm{T})=\frac{1}{\mathrm{~m}(\mathrm{~T})}
$$

Odgovarajuća srednja vremena do korektivne i preventivne zamene su:

$$
v(T)=\frac{1}{z(T)}=\frac{m(T)}{F(T)}
$$




$$
w(T)=\frac{1}{u(T)}=\frac{m(T)}{R(T)}
$$

Za određeni period eksploatacije $\mathrm{T}_{\mathrm{e}}$ srednji broj svih zamena je:

$$
\mathrm{N}_{\mathrm{e}}(\mathrm{T})=\frac{\mathrm{T}_{\mathrm{e}}}{\mathrm{M}(\mathrm{T})}
$$

pri čemu je srednji broj korektivnih zamena:

$\mathrm{N}_{\mathrm{ek}}(\mathrm{T})=\frac{\mathrm{Te}_{\mathrm{e}}(\mathrm{T})}{\mathrm{M}(\mathrm{T}) \mathrm{v}(\mathrm{T})}=\mathrm{N}_{\mathrm{e}}(\mathrm{T}) \mathrm{F}(\mathrm{T})$

i srednji broj preventivnih zamena:

$\mathrm{N}_{\mathrm{ep}}(\mathrm{T})=\frac{\mathrm{T}_{\mathrm{e}} \mathrm{m}(\mathrm{T})}{\mathrm{M}(\mathrm{T}) \mathrm{W}(\mathrm{T})}=\mathrm{N}_{\mathrm{e}}(\mathrm{T}) \mathrm{R}(\mathrm{T})$

Smanjenje broja otkaza (korektivnih zamena) preventivnim zamenama u odnosu na slučaj kada se preventivne zamene ne vrše, dobija se iz (26) i (46):

$$
n_{e}(T)=\frac{N_{k}}{N_{e k}(T)}=\frac{M(T)}{M_{k} F(T)}
$$

Pouzdanost $i$ raspoloživost sistema koji sadrži element sa rastucim tokom otkaza

Element sa rastućim tokom otkaza, sa ostatkom sistema u čijem sastavu se nalazi, povezan je redno $u$ smislu pouzdanosti, tako da je ukupan tok otkaza:

$$
\lambda_{s}(T)=z(T)+\lambda_{o s}
$$

Redovnom preventivnom zamenom elementa sa rastućim tokom otkaza uspostavlja se stacionarno stanje, pri kome ekvivalentni intenzitet otkaza na osnovu (40) ima neku određenu vrednost, pošto za dato $T$ srednje vreme do zamene $\mathrm{m}(\mathrm{T})$ i funkcija raspodele verovatnoće do otkaza
F(T) imaju tačno određene vrednosti. Pouzdanost sistema je:

$$
R_{s}(t)=e^{-\lambda_{s} t}
$$

gde je $\lambda_{\mathrm{s}}$ recipročna vrednost srednjeg vremena do otkaza sistema. Srednja vrednost vremena do zamene elementa (preventivne ili korektivne zamene elementa sa rastućim tokom otkaza ili nekog drugog elementa sistema) iznosi:

$$
\mathrm{m}_{\mathrm{s}}(\mathrm{T})=\frac{1}{\mathrm{z}(\mathrm{T})+\mathrm{u}(\mathrm{T})+\lambda_{\mathrm{os}}}
$$

Srednje vreme bilo koje zamene bilo kog elementa je:

$$
T_{s}=\frac{z(T) T_{k}+u(T) T_{p}+\lambda_{o s} T_{o s}}{z(T)+u(T)+\lambda_{o s}}
$$

Srednje vreme između zamena je:

$$
M_{s}(T)=m_{s}(T)+T_{s}(T)
$$

$\mathrm{Na}$ osnovu prethodnih izraza raspoloživost sistema je:

$$
\begin{aligned}
& A_{s}(T)=\frac{m_{s}(T)}{M_{s}(T)}= \\
& =\frac{1}{1+z(T) T_{k}+u(T) T_{p}+\lambda_{o s} T_{o s}}
\end{aligned}
$$

Srednji broj ukupnih zamena $u$ periodu $\mathrm{T}_{\mathrm{e}}$ je:

$$
N_{s}(T)=\frac{T_{e}}{M_{s}(T)}
$$

Srednji broj zamena elemenata sa rastućim tokom otkaza je:

korektivnih $\mathrm{N}_{\mathrm{sk}}(\mathrm{T})=\mathrm{N}_{\mathrm{s}}(\mathrm{T}) \mathrm{z}(\mathrm{T}) \mathrm{m}_{\mathrm{s}}(\mathrm{T})$ (56)

preventivnih $\quad \mathrm{N}_{\mathrm{sp}}(\mathrm{T})=\mathrm{N}_{\mathrm{s}}(\mathrm{T}) \mathrm{u}(\mathrm{T}) \mathrm{m}_{\mathrm{s}}(\mathrm{T})$

dok je srednji broj korektivnih zamena elemenata ostatka sistema:

$$
N_{o s}(T)=N_{s}(T) \lambda_{o s} m_{s}(T)
$$


U slučaju kada se ne vrši preventivna zamena elementa sa rastućim tokom otkaza, za izračunavanje pouzdanosti sistema mora se poći od opšteg izraza:

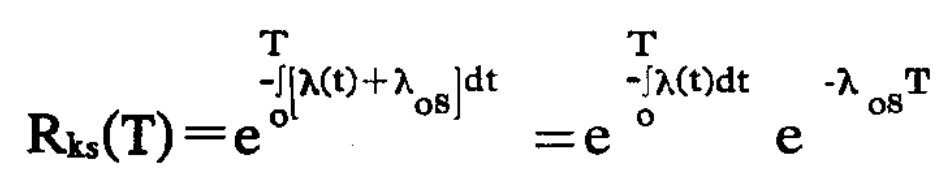

Srednje vreme do otkaza je:

$$
\mathrm{m}_{\mathrm{ks}}=\int_{\mathrm{o}}^{\infty} \mathrm{R}_{\mathrm{ks}}(\mathrm{T}) \mathrm{dT}
$$

ali se može uzeti da približno iznosi:

$$
\mathrm{m}_{\mathrm{ks}} \approx \frac{1}{\frac{1}{\mathrm{~m}_{\mathrm{k}}}+\lambda_{\mathrm{os}}}
$$

Tada je srednje vreme između otkaza (korektivnih zamena):

gde je:

$$
\mathbf{M}_{\mathrm{ks}}=\mathrm{m}_{\mathrm{ks}}+\mathrm{T}_{\mathrm{ks}}
$$

$$
T_{k s}=\frac{\frac{1}{m_{k}} T_{k}+\lambda_{o s} T_{o s}}{\frac{1}{m_{k}}+\lambda_{o s}}=\frac{T_{k}+\lambda_{o s} m_{k} T_{o s}}{1+\lambda_{o s} m_{k}}
$$
stema je:

U ovom slučaju raspoloživost si-

$$
A_{k s}=\frac{m_{k s}}{M_{k s}}=\frac{m_{k}}{m_{k}+T_{k}+\lambda_{\text {os }} m_{k} T_{o s}}
$$

Srednji broj ukupnih otkaza u toku perioda eksploatacije $T_{e}$ je:

$$
\mathbf{N}_{\mathrm{ok}}=\frac{\mathbf{T}_{\mathrm{e}}}{\mathbf{M}_{\mathrm{ks}}}
$$

pri čemu je srednji broj otkaza elementa sa rastućim tokom otkaza:

$$
\mathbf{N}_{\mathrm{oe}}=\mathrm{N}_{\mathrm{ok}} \frac{\mathrm{m}_{\mathrm{ks}}}{\mathrm{m}_{\mathrm{k}}}
$$

a srednji broj otkaza elementa ostatka sistema u tom periodu:

$$
\mathrm{N}_{\mathrm{oo}}=\mathrm{N}_{\mathrm{os}} \lambda_{\mathrm{os}} \mathrm{m}_{\mathrm{ks}}
$$

$\mathrm{Na}$ osnovu (56), (58), (65) i (66) dobija se da se broj otkaza sistema u slučaju kada se vrše preventivne zamene u odnosu na slučaj kada se preventivne zamene ne vrše $n_{s}$ je:

$$
n_{s}=\frac{M_{s}(T)}{m_{s}(T) M_{k s}\left[z(T)+\lambda_{o s}\right]}
$$

\section{Numerički primer}

Izvedeni izrazi omogućavaju da se u praksi za tehničke sisteme koji sadrže elemente sa rastućom vrednošću toka otkaza postavi optimalni proces njihove preventivne zamene za izabrani kriterijum optimizacije. Primena izvedenih izraza prikazana je na primeru tehničkog sistema koji, pored elemenata koji podležu eksponencijalnoj raspodeli verovatnoće vremena do otkaza, sadrži i element čija raspodela verovatnoće vremena do otkaza podleže Vejbulovoj raspodeli sa parametrom $\beta=4$, tako da trenutna vrednost toka otkaza neprekidno raste, sve dok element ne prestane da funkcioniše. Vejbulova raspodela je izabrana iz dva razloga: prvo, zato što spada među nekoliko raspodela verovatnoća kojoj podleže vreme do otkaza velikog broja različitih elemenata $\mathbf{i}$, drugo, što je u stručnoj literaturi, prilikom analiza i izračunavanja optimalnog perioda preventivne zamene najčešće korišcena ta raspodela, tako da se dobijeni rezultati i zaključci mogu upoređivati sa rezultatima do kojih su došli drugi autori. Jasno je da je i drugi razlog najvećim delom posledica prvog.

\section{Ulazni podaci}

$$
\begin{array}{r}
\text { Parametri Vejbulove raspodele } \\
\beta=4, \eta=200 \mathrm{~h} .
\end{array}
$$


Vrednost toka otkaza tehničkog sistema bez elementa sa rastućom vrednošću toka otkaza $\lambda=4 \cdot 10^{-4} 1 / \mathrm{h}$.

Troškovi korektivne zamene elementa sa rastućim tokom otkaza $C_{k}=$ $=600 \mathrm{n} . \mathrm{j}$. (novčanih jedinica).

Troškovi preventivne zamene elementa sa rastućim tokom otkaza $\mathrm{C}_{\mathrm{p}}=$ $=300 \mathrm{n} . \mathrm{j}$.

Prosečni troškovi zamene nekog elementa sa konstantnim tokom otkaza $\mathrm{C}_{\mathrm{os}}=600$ n.j.

Srednje vreme obnavljanja korektivne zamene elementa sa rastućom vrednošću toka otkaza $\mathrm{T}_{\mathrm{k}}=24 \mathrm{~h}$.

Srednje vreme obnavljanja preventivne zamene elementa sa rastućom vrednošću toka otkaza $T_{p}=4 \mathrm{~h}$.

Srednje vreme obnavljanja korektivne zamene nekog elementa sa konstantnom vrednošću toka otkaza $T_{\text {os }}=$ $=16 \mathrm{~h}$.

Prihod po času rada $D_{o}=50$ n.j./h.

Period eksploatacije $T_{e}=8760 \mathrm{~h}$.

\section{Dobijeni rezultati}

Kao i izvedeni izrazi, dobijeni rezultati se odnose na element sa rastućim tokom otkaza kada se ne vrše i kada se vrše njegove preventivne zamene i na tehnički sistem u čiji sastav taj element ulazi. Svi rezultati su dobijeni korišćenjem posebnog programa za računar, koji je realizovan tako da zavisnosti između pojedinih veličina mogu da se predstave tabelarno i u obliku dijagrama. Ako se optimalne vrednosti perioda preventivne zamene mogu dobiti direktno traženjem ekstremnih vrednosti funkcija (4), (5) i (7), program je urađen tako da se one dobijaju u preseku krivih (4) $\mathrm{i}$ (17); (5) i (15); (7) i (12). Na taj način postignuta je visoka tačnost dobjenih rezultata, što u suprotnom ne bi bi- lo obezbeđeno zbog "blagih" minimuma i maksimuma funkcije kriterijuma optimizacije.

Rezultati dobijeni za element sa rastućim tokom otkaza dati su $u$ tabeli 1 . Sve vrednosti odnose se na slučaj kada se preventivne zamene ne bi vr. šile (prva kolona rezultata; period preventivne zamene tada ima beskonačno veliku vrednost) i na tri optimalne vrednosti perioda preventivne zamene $T_{c}, T_{a} i T_{d}$. Svi ti rezultati mogu se izračunati i za bilo koju drugu vrednost perioda preventivne zamene. Iz tab. 1 vidi se koliko se procenata od najpovoljnijih vrednosti druga dva kriterijuma koristi ako se proces preventivnih zamena tako postavi da jedan od kriterijuma ima najpovoljniju $(100 \%$ ) vrednost (na red. br. 7,11 . i 15 . tabele 1). Kako bi se te veličine menjale kada bi se period preventivne zamene menjao od 95 do 195 h prika. zano je na slici 1 .

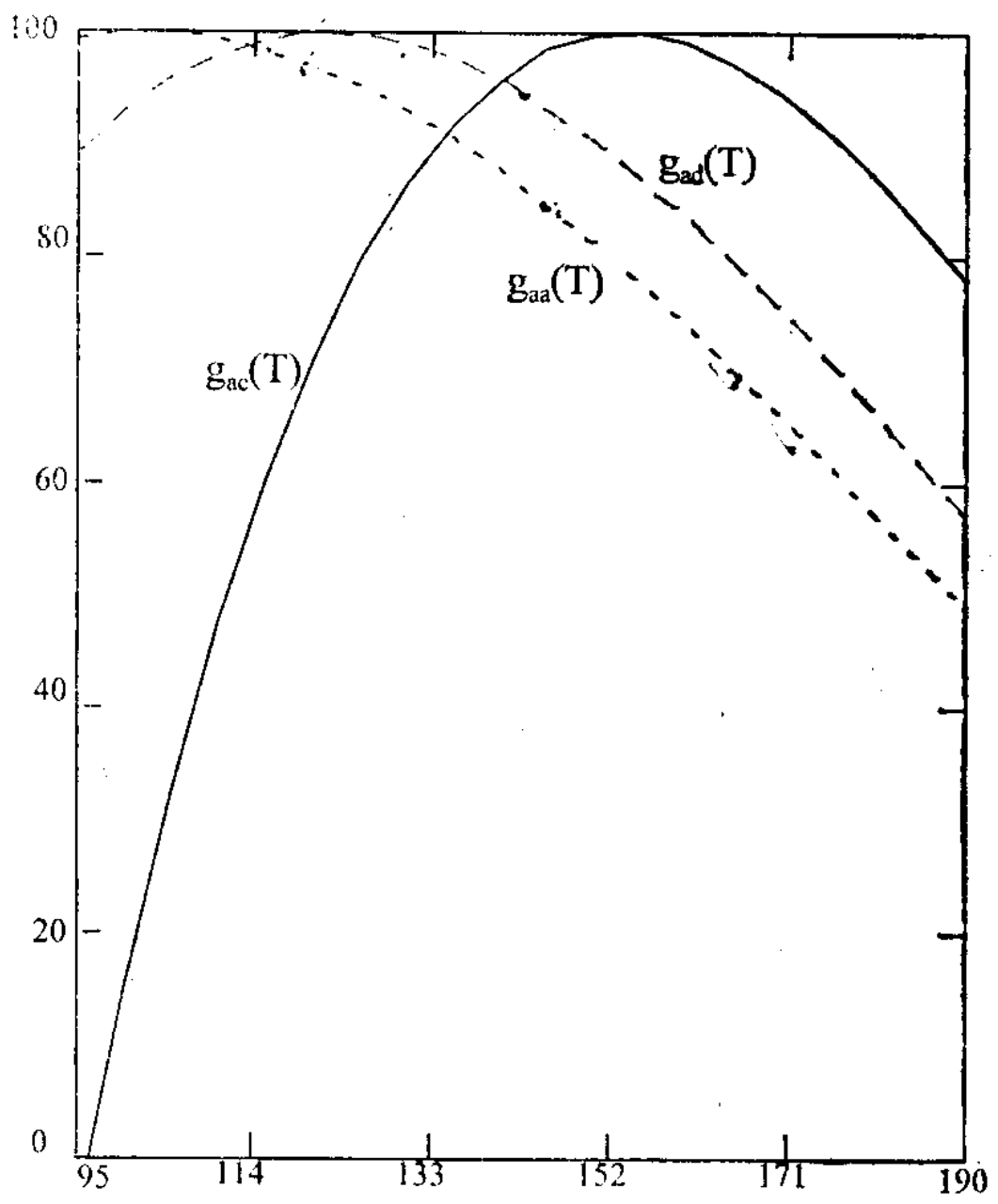

Sl. 1 - Zavisnost dobitka koji se ostvaruje preventivnim zamenama za sva tri kriterijuma optimizacije od perioda preventivne zamene 
Tabela 1

\begin{tabular}{|c|c|c|c|c|c|}
\hline \multirow[b]{2}{*}{$\begin{array}{l}\text { Redni } \\
\text { broj }\end{array}$} & \multirow[b]{2}{*}{ Veličina } & \multirow{2}{*}{$\begin{array}{l}\text { Prev. za- } \\
\text { mene se } \\
\text { ne vrše } \\
\mathbf{i}=\mathbf{k}\end{array}$} & \multicolumn{3}{|c|}{ Kriterijum optimizacije } \\
\hline & & & $\underset{i=c}{\text { Troškovi }}$ & $\begin{array}{c}\text { Raspolo- } \\
\text { živost } \\
\mathbf{i}=\mathbf{a}\end{array}$ & $\underset{i=d}{\text { Prihod }}$ \\
\hline 1. & $T_{i}[h]$ & $\infty$ & 153,223 & 101,796 & 121,342 \\
\hline 2. & $\mathrm{~m}_{\mathrm{i}}[\mathrm{h}]$ & 181,280 & 143,601 & 100,455 & 118,173 \\
\hline 3. & $M_{i}[h]$ & 205,280 & 153,429 & 105.753 & 124,708 \\
\hline 4. & $C_{i}[n . j . / h]$ & 3,309788 & 2,697927 & 3,180269 & 2,860329 \\
\hline 5. & $\mathrm{C}_{\mathrm{ri}}$ & 1,00 & 0,815136 & 0,960868 & 0,864203 \\
\hline 6. & $\mathrm{G}_{i}[\%]$ & 0 & 18,47 & 3,91 & 13,58 \\
\hline 7. & $g_{i}[\%]$ & 0 & 100,00 & 79,11 & 88,43 \\
\hline 8. & $A_{i}$ & 0,883087 & 0,935942 & 0,949900 & 0,947603 \\
\hline 9. & $A_{r i}$ & 1,00 & 1,059583 & 1,075659 & 1,073058 \\
\hline 10. & $\mathrm{G}_{i}[\%]$ & 0 & 5,98 & 7,57 & 7,31 \\
\hline 11. & $\mathrm{~g}_{\mathrm{i}}[\%]$ & 0 & 21,17 & 100,00 & 94,31 \\
\hline 12. & $D_{i}[n . j . / h]$ & 41,232 & 44,272 & 44,474 & 44,670 \\
\hline 13. & $D_{r i}$ & 1,00 & 1,073742 & 1,078643 & 1,083387 \\
\hline 14. & $\mathrm{G}_{\mathrm{i}}[\%]$ & 0 & 7,37 & 7,86 & 8,34 \\
\hline 15. & $\mathrm{~g}_{\mathrm{i}}[\%]$ & 0 & 73,46 & 96,56 & 100,00 \\
\hline 16. & $D_{\mathrm{i}} *[\mathrm{n} . \mathrm{j} . / \mathrm{h}]$ & 8,768 & 5,728 & 5,526 & 5,330 \\
\hline 17. & $\mathrm{~d}_{\mathrm{ri}}$ & 4,702 & 7,729 & 8,048 & 8,380 \\
\hline 18. & $\mathbf{z}_{\mathrm{i}}$ & 1 & 20,29 & 6,462 & 10,72 \\
\hline 19. & $\mathbf{u}_{\mathrm{i}}$ & 1 & 49,34 & 93,09 & 73,90 \\
\hline 20. & $v_{i}[h]$ & 1 & 492,770 & 1547,604 & 932,592 \\
\hline 21. & $w_{i}[h]$ & 1 & 202,659 & 107,428 & 135,320 \\
\hline 22. & $\mathbf{N}_{\mathbf{k i}}$ & 42,673319 & 16,638302 & 5,376780 & 8,901002 \\
\hline 23. & $\mathbf{N}_{\mathrm{pi}}$ & 1 & 40,456430 & 77,457838 & 61,343315 \\
\hline 24. & $\mathbf{N}_{\mathbf{i}}$ & 42,673319 & 57,094732 & 82,834618 & 70,244317 \\
\hline 25. & $\mathrm{n}_{\mathrm{i}}$ & 1,00 & 2,564764 & 7,936593 & 4,794215 \\
\hline
\end{tabular}


Prilikom definisanja uslova koje treba da zadovolji vrednost optimalnog perioda preventivne zamene, ustanovljeno je da granice opsega promena $\mathrm{T}, \mathrm{u}$ kojima se nalaze optimalna rešenja za sva tri kriterijuma, određuju odnosi $C_{p} / C_{k}=1 / 2$ i $T_{p} / T_{k}=1 / 6$. Optimalne vrednosti perioda preventivnih zamena, pri kojima prihod po jedinici vremena ima maksimalnu vrednost za razne vrednosti prihoda po jedinici vremena rada $D_{0}$, date su $u$ tabeli 2. Iz nje se vidi da se, kada se $\mathrm{D}_{\mathrm{o}}$ menja od $\mathrm{C}_{\mathrm{c}}=2,698$ do $\infty$, vrednost optimalnog perioda preventivne zamene menja od $T_{c}=153,223 \mathrm{~h}$ do $T_{a}=$ $=101,796 \mathrm{~h}$. To znači da $\mathrm{i}$ rezultati dobijeni za konkretni primer pokazuju da je prihod po jedinici vremena opštiji kriterijum optimizacije od raspoloživosti i troškova po jedinici vremena rada, pošto ta dva kriterijuma optimizacije daju isti rezultat kao i prvi kriterijum za posebne vrednosti parametra $D_{0}$. Da bi se ova osobina prenela i na tehničke sisteme kod kojih se korisnost ne može izraziti u novčanim jedinicama po času rada, parametar $D_{o}$ se može shvatiti kao koeficijent značaja ispravnog funkcionisanja sistema (što je značaj ispravnosti rada veći, odnosno, posledice zastoja nepovoljnije, utoliko taj koeficijent treba da ima veću vrednost). U tom slučaju pre- ko parametra $D_{0}$ rešava se problem uvođenja kompromisnog kriterijuma raspoloživosti i troškova, što je uočeno kao potreba [8] $u$ praksi inženjerstva održavanja.

Kriva koja povezuje vrednosti troškova po jedinici vremena rada sa vrednostima raspoloživosti za dati brojčani primer, prikazana na sl. 2, predstavlja krivu kompromisa optimalnih rešenja (od tačke A do tačke C) u smislu Pareto višekriterijumske (dvokri-

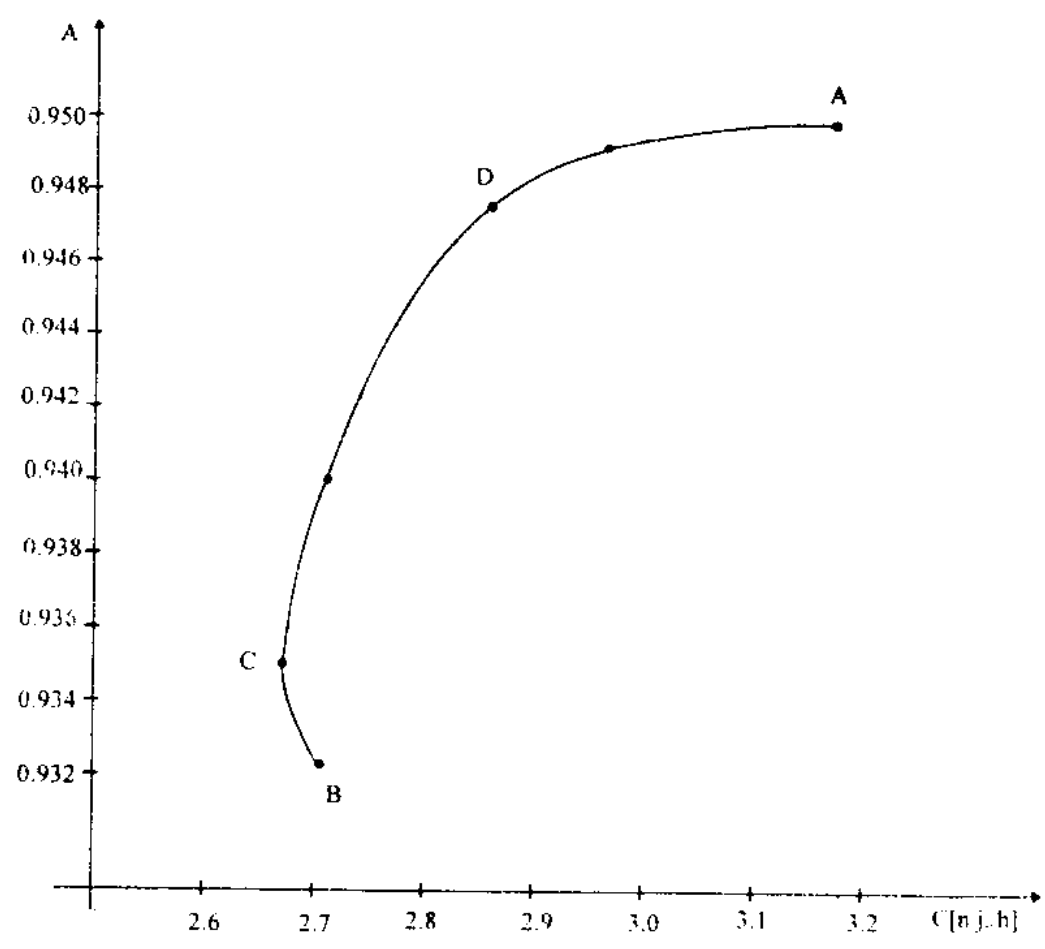

Sl. 2 - Kriva optimizacije:

A-C Neinferiorna rešenja (Pareto optimizacija)

Tabela 2

\begin{tabular}{|l|l|c|c|c|c|}
\hline \multicolumn{2}{|c|}{$\begin{array}{c}\text { Struktura i da li se vrši } \\
\text { preventivna zamena }\end{array}$} & \multicolumn{3}{c|}{ Pouzdanost } & Raspolo- \\
\cline { 2 - 6 } & živost \\
\hline $\begin{array}{l}\text { Elementi sa rast. } \\
\text { tokom otkaza }\end{array}$ & bez prev. zamene & 0,939413 & 0,367879 & 0,006330 & 0,883087 \\
\cline { 2 - 6 } & sa prev. zamenom & 0,939413 & 0,878770 & 0,823783 & 0,949900 \\
\hline $\begin{array}{l}\text { Sistemi bez elem. sa rast. } \\
\text { tokom otkaza }\end{array}$ & 0,960789 & 0,923116 & 0,886920 & 0,993641 \\
\hline Tehnički sistem & bez prev. zamene & 0,902578 & 0,339596 & 0,005614 & 0,877960 \\
\hline & sa prev. zamenom & 0,902578 & 0,811207 & $\mathbf{0 , 7 3 0 6 3 0}$ & $\mathbf{0 , 9 4 4 1 5 9}$ \\
\hline
\end{tabular}


terijumske) optimizacije, jer se ne može naći tačka sa većom raspoloživošću od raspoloživosti u tački $\mathrm{C}$, a da se ne povećaju troškovi i ne može se naći tačka sa manjim troškovima od troškova u tački A a da se ne smanji raspoloživost. Deo krive od tačke C do tačke B ne predstavlja deo kompromisne krive, pošto te tačke imaju i manju raspoloživost $i$ veće troškove od raspoloživosti i troškova u tački $\mathrm{C}$ krive.

Treba naglasiti da u slučaju tehničkog sistema kod kojeg je poznat prihod po svakom času rada (npr. $D_{0}=$ $=50 \mathrm{n} . \mathrm{j} . / \mathrm{h}$ ) kao najpovoljniji period preventivne zamene treba uzeti $T=T_{d}$ $\left(T_{d}=121,342 \mathrm{~h}\right)$ i to je optimalno, a ne kompromisno rešenje. Kod ostalih tehničkih sistema vrednost $D_{0}$ se procenjuje prema značaju raspoloživosti $\mathrm{u}$ odnosu na troškove. Posebnu grupu tehničkih sistema predstavljaju sredstva naoružanja i vojne opreme kod kojih je, posebno u toku borbenih dejstava, ispravno funkcionisanje od velikog značaja. Kod njih se proces preventivnih zamena može postaviti tako da u miru odgovara tački C (minimalni troškovi), a u ratu tački A (maksimalna raspoloživost).

Pouzdanosti i raspoloživosti tehničkog sistema koji sadrži element sa rastućim tokom otkaza mogu se izračunati za bilo koju vrednost perioda preventivne zamene. Ovde ce to biti učinjeno za $\mathrm{T}=\mathrm{T}_{\mathrm{a}}=101,796$. Iz tabele 1 vidi se da su tada ekvivalentni intenziteti zamena: korektivnih $\mathrm{z}_{\mathrm{a}}=$ $=6,462 \cdot 10^{-4} 1 / \mathrm{h}$ i preventivnih $\mathrm{u}_{\mathrm{a}}=$ $=93,09 \cdot 10^{-4} 1 / \mathrm{h}$, tako da je:

$$
\begin{aligned}
& \lambda_{s}=\mathrm{z}_{\mathrm{a}}+\lambda_{\text {os }}=10,462 \cdot 10^{-4} \frac{1}{\mathrm{~h}} \\
& \mathrm{R}_{\mathrm{s}}(\mathrm{t})=\mathrm{e}^{-0,0010462 \mathrm{t}} \\
& \mathrm{m}_{\mathrm{s}}=\frac{10^{4}}{6,462+93,09+4}=96,570
\end{aligned}
$$

$$
\mathrm{T}_{\mathrm{s}}=\frac{6,462 \cdot 24+93,09 \cdot 4+4 \cdot 16}{103,552}=5,712
$$

$$
\begin{aligned}
& M_{s}=m_{s}+T_{s}=102,282 \\
& A_{s}=\frac{m_{s}}{M_{s}}=0,944159
\end{aligned}
$$

Srednji broj zamena $\mathrm{u}$ toku perioda $\mathrm{T}_{\mathrm{e}}=8760 \mathrm{~h} \mathrm{je:}$

$$
\begin{aligned}
& \mathrm{N}_{\mathrm{os}}=3,309 \quad \mathrm{~N}_{\mathrm{sk}}=5,344 \quad \mathrm{~N}_{\mathrm{sp}}=76,992 \\
& \mathrm{~N}_{\mathrm{s}}=85,645
\end{aligned}
$$

U slučaju kada se ne vrše preventivne zamene elemenata sa rastućim tokom otkaza pouzdanost sistema je:

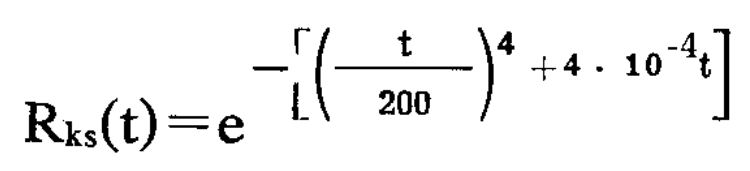

Približne vrednosti srednjeg vremena do korektivne zamene, srednjeg vremena trajanja zamene i srednjeg vremena između zamena na osnovu (61), (62) i (63) su:

$\mathrm{m}_{\mathrm{ks}}=169,024 \quad \mathrm{~T}_{\mathrm{ks}}=23,495 \mathrm{~h}$

$M_{\mathrm{ks}}=192,519 \mathrm{~h}$

tako da je u tom slučaju raspoloživost sistema (64):

$$
A_{k s}=\frac{m_{k s}}{M_{k s}}=0,877960
$$

Srednji broj korektivnih zamena je:

$$
\mathrm{N}_{\mathrm{oo}}=3,076 \quad \mathrm{~N}_{\mathrm{oc}}=42,426 \quad \mathrm{~N}_{\mathrm{ok}}=45,502
$$

Preventivnim zamenama smanjuje se broj otkaza sistema u odnosu na slučaj kada se zamene ne vrše $n_{s}$ puta:

$$
\mathrm{n}_{\mathrm{s}}=\frac{\mathrm{N}_{\mathrm{ok}}}{\mathrm{N}_{\mathrm{os}}+\mathrm{N}_{\mathrm{sk}}}=\frac{45,502}{3,309+5,344}=5,259
$$

$\mathrm{Na}$ osnovu (69) i (70) izračunata je pouzdanost sistema sa $\mathrm{i}$ bez preventivnih zamena po isteku 100,200 i 
300 h rada. Dobijeni rezultati zajedno sa pouzdanošću elemenata sa rastućim tokom otkaza i sistema bez tog elementa, prikazani su u tabeli 3 , u koju su unete i odgovarajuće vrednosti raspoloživosti. Pouzdanost sistema, kada se preventivne zamene vrše po- sle $100 \mathrm{~h}$, nije računata po izrazu (69), jer ne može biti manja od pouzdanosti sistema kod kojeg se preventivne zamene ne vrše. Te dve pouzdanosti su iste, pošto se razmatra slučaj kada se prva preventivna zamena obavlja po isteku $T_{d}=101,796 \mathrm{~h}$.

Tabela 3

\begin{tabular}{|c|c|c|c|c|c|}
\hline $\begin{array}{c}\text { Redni } \\
\text { broj }\end{array}$ & $\begin{array}{c}\mathrm{D}_{\mathrm{o}} \\
{[\mathrm{n} . \mathrm{j} / \mathrm{h}]}\end{array}$ & $\begin{array}{c}\mathrm{T}=\mathrm{T}_{\mathrm{d}} \\
{[\mathrm{h}]}\end{array}$ & $\begin{array}{c}\mathrm{C}(\mathrm{T}) \\
{[\mathrm{n} . \mathrm{j} / \mathrm{h}]}\end{array}$ & $\mathrm{A}(\mathrm{T})$ & $\begin{array}{c}\text { Oznaka } \\
\text { tačke } \\
\text { na sl. 2 }\end{array}$ \\
\hline 1. & 0 & 159,279 & 2,703 & 0,932928 & $\mathrm{~B}$ \\
\hline 2. & 2.698 & 153,223 & 2,698 & 0,935942 & $\mathrm{C}$ \\
\hline 3. & 10 & 142,255 & 2,714 & 0,940849 & \\
\hline 4. & 50 & 121,342 & 2,860 & 0,947603 & $\mathrm{D}$ \\
\hline 5. & 100 & 113,876 & 2,958 & 0,948996 & \\
\hline 6. & 500 & 104,817 & 3,116 & 0,949841 & \\
\hline 7. & 1000 & 103,358 & 3,146 & 0,949884 & \\
\hline 8. & $\infty$ & 101,796 & 3,180 & 0,949900 & $\mathrm{~A}$ \\
\hline
\end{tabular}

$\mathrm{Na}$ osnovu rezultata datih $\mathrm{u}$ tabeli 3 vidi se da se niska pouzdanost i raspoloživost sistema koji sadrži element sa rastućim tokom otkaza može znatno povećati preventivnom zamenom tog elementa. Na osnovu broja otkaza u periodu $T_{e}$ mogu se izračunati očekivani troškovi po jedinici vremena rada sistema kada se preventivne zamene ne vrše $C_{k s}$ i kada se preventivne zamene vrše $C_{s}$. Dobija se da je:

$$
\mathrm{C}_{\mathrm{ks}}=3,549040 \quad \text { i } \quad \mathrm{C}_{\mathrm{s}}=3,420382
$$

tako da su relativni troškovi sistema:

$$
\mathrm{C}_{\mathrm{sr}}=0,963748
$$

Dobijene vrednosti su nešto veće od vrednosti iz tabele 1 (kolona 1 red. br. 4 i kolona 4 red. br. 4 i 5) pošto se čine dodatni troškovi pri zameni komponenti sistema sa konstantnim tokom otkaza.

\section{Zaključak}

Izvedeni izrazi i izračunate vrednosti u slučaju kada se ne vrše preventivne zamene elemenata sa rastućim tokom otkaza pokazuju da prisustvo takvog elementa u sastavu tehničkog sistema može znatno da degradira karakteristike pouzdanosti i raspoloživosti sistema u celini i da pove-ća ukupne troškove održavanja. Preventivnim zamenama elemenata sa rastućim tokom otkaza sprečavaju se česti nepredviđeni zastoji sistema zbog otkazivanja tog elementa. Definisan je veliki broj parametara čije se vrednosti menjaju $u$ zavisnosti od dužine perioda od poslednje zamene do sledeće preventivne zamene.

Za sve tehničke sisteme kod kojih je korisnost upotrebe srazmerna vremenu ispravnog rada $\mathrm{i}$ kada se koeficijent te srazmernosti $D_{0}$ može kvan- 
tifikovati, osnovni kriterijum optimizacije je prihod po jedinici vremena (razlika ostvarene nadoknade za rad sistema i troškova zamena) ili, što je isto, zbir izgubljene dobiti zbog zastoja sistema i troškova zamena. Optimalna vrednost perioda preventivne zamene u tom slučaju, pored koeficijenta $D_{o}$, zavisi $i$ od vremena potrebnog za vršenje zamena $T_{k}$ i $T_{p} i$ troškova zamena $C_{k}$ i $C_{p}$. Maksimalna raspoloživost koja se može postići ograničena je vrednostima $T_{k} i T_{p} i$ ne zavisi od $C_{k}$ i $C_{p}$, što važi u slučaju kada $\mathrm{D}_{\mathrm{o}} \rightarrow \infty$. Minimalni troškovi koji se mogu ostvariti ograničeni su vrednostima $C_{k}$ i $C_{p}$ i ne zavise od $T_{k}$ i $T_{p}$, što važi $i$ u slučaju kada je $D_{o}$ jednako troškovima zamena po jedinici vremena rada. Na taj način je pokazano da su raspoloživost i troškovi zamena, kao kriterijumi optimizacije, poseban slučaj prihoda po jedinici rada, jer se iz opšteg uslova koji važi za taj kriterijum dobijaju za posebne vrednosti koeficijenta $D_{0}$. To omogućava da se i za ostale tehničke sisteme može formirati kriva kompromisnih optimalnih rešenja čije krajnje tačke (sl. 2 tačke A i C) predstavljaju optimalna rešenja kada su kriterijumi optimiza-

\footnotetext{
Literatura:
}

[1] Todorović, J.: Inženjerstvo održavanja tehničkih sistema - Maintainability Engineering, JUMV, Beograd, 1993.

[2] Barlow, R. G., Proshan, F.: Mathematical Theory of Reliability, John Wiley \& Sons, New York, 1965.

[3] Vukadinović, S., Teodorović, D.: Elementi teorije pouzdanosti i teorije obnavljanja tehničkih sistema, Privredni pregled, Beograd, 1979.

[4] Peković, T., Todorović, J.: Optimal Block replacement strategy, Proceedings of the 3rd Balkan Conference on Operational Research, Thessaloniki, 1996. cije raspoloživost i troškovi zamena, a iz klasične višekriterijumske optimizacije poznato je da se optimalno rešenje uvek nalazi na toj krivi. Izgled te krive i poznavanja značenja koeficijenta $D_{o}$ olakšavaju izbor optimalnog rešenja u svakom konkretnom slučaju.

Ekvivalentni intenziteti korektivne i preventivne zamene omogućavaju da se, u uslovima ustaljene redovne preventivne zamene, komponente sa rastućim tokom otkaza tretiraju kao i komponente sa konstantnim tokom otkaza pri analizi karakteristika pouzdanosti i raspoloživosti tehničkih sistema. Izloženi postupak omogućava analizu tehničkih sistema složenije strukture koji sadrže dva i više elemenata sa rastućim tokom otkaza. To što su izrazi za veliki broj parametara dati u zavisnosti od perioda preventivne zamene omogućava: prvo, da se izvrši analiza karakteristika svake komponente sa rastućim tokom otkaza, posebno u širokom opsegu promena perioda preventivne zamene $i$, drugo, da se na osnovu rezultata tih analiza izvrši optimizacija procesa preventivne zamene za izabrani kriterijum, na nivou tehničkog sistema.

[5] Peković, T.: Određivanje optimalnog perioda kombinovane preventivne zamene, Vojnotehnički glasnik, 1/1994.

[6] Peković, T.: Određivanje optimalnog perioda grupne preventivne zamene, Vojnotehnički glasnik, 3-4/1994.

[7] Peković, T.: Optimalna strategija preventivne zamene, Vojnotehnički glasnik, 5/1994.

[8] Minić, S., Arsenić, Ž., Todorović, J.: "Trade off" model preventivnog održavanja tehničkih sistema, Vojnotehnički glasnik, 6/1996.

[9] Spravočnik u 10 tomova, Nadežnost i effektivnost $v$ tehnike, tom 8: Eksploatacija i remont, Mašinopostrenie, Moskva, 1990. 